\title{
Evidence-based Treatment of Tuberculosis for Children: The Unfinished Agenda
}

\author{
SOUMYa SWAMinathan
}

Senior Deputy Director, Tuberculosis Research Centre, Chennai; and Coordinator, Neglected Priorities Research, TDR, WHO, Geneva.

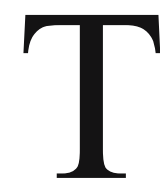

hough an estimated 1 million new cases of tuberculosis (TB) occur in children worldwide each year, pediatric TB has not been given the same priority as its adult counterpart(1). Advances in diagnosis and treatment are lagging behind - the major limitation in performing treatment trials in children is the lack of a definitive gold standard for diagnosis and monitoring. As a result, regimens and dosages of anti-TB drugs tested in adults are often extrapolated to children. The efficacy of short-course chemotherapy (SCC) regimens for the treatment of pulmonary TB was first demonstrated in adults in the1970s; this was followed by trials for extrapulmonary and childhood TB. Even before SCC became the norm, the phenomenon of "lag phase" in mycobacteria exposed to anti-TB drugs in vitro was described and led to the concept of intermittent treatment(2). Thrice, twice and even once-weekly regimens were tested, most of the trials being conducted at the UK Medical Research Council sites in Madras, Hongkong and East Africa(3). The results with thrice-weekly treatment were encouraging; lower dosing frequency led to higher failure and relapse, especially in patients who were rapid acetylators of isoniazid. However, a Cochrane review comparing daily and thrice-weekly treatment in adults identified only one eligible trial and concluded that while cure rate was similar, relapses were higher in the intermittent $\operatorname{arm}(4)$.

In this issue of the journal, Menon, et al.(5) performed a meta-analysis of trials comparing daily and intermittent treatment in children. The studies vary widely in terms of patient profile, type of intermittent regimen tested (daily followed by intermittent, thrice-weekly followed by twiceweekly, twice-weekly throughout), drug dosages, use of directly observed treatment (DOT), follow-up time and study end-points selected. Further, the use of clinical/radiographic endpoints, unless validated and made as objective as possible, leads to subjectivity in assessment of cure. Using the Jadad score, which assesses the quality of trials based on the appropriate use and reporting of randomization and patient losses, only 1 of the four included trials scored 3 out of 5. Overall, favorable responses were high, and death, relapse and adverse events low, with all the regimens used, there was a trend to a lower "cure" rate with the use of twice-weekly regimens. However, when one study was excluded during the sensitivity analysis, the odds ratio approached 1.0 suggesting that this study was driving the results. None of the studies tested a fully intermittent thriceweekly regimen, which is currently recommended for use in the Indian Revised National TB Control Program. Perhaps, due to lack of available baseline data, the authors have not attempted an analysis of the other factors that predispose to poor outcomes young age, associated malnutrition, suboptimal dosage, non-compliance etc. Of course, HIV is unlikely to have been a confounding factor as most of these studies were conducted in the 1980s and 1990s in areas of low prevalence. HIV, however, is an important factor to consider during analysis of trials being planned or conducted now. Malabsorption of drugs has been documented in patients with advanced HIV and could contribute to poor out- 
comes including higher death, recurrence and acquisition of drug resistance(6). Recent pharmacokinetic studies in children with $\mathrm{TB}$, conducted mostly in south Africa, have suggested that the dosage of the first line drugs, including isoniazid and rifampicin, need to be critically reviewed $(7,8)$.

This meta-analysis highlights the gaps in knowledge and the lack of an evidence base to recommend a safe and efficacious intermittent antiTB regimen for children. Clinical trials performed now need to conform to CONSORT guidelines and should follow preset case definitions and endpoints. A more pragmatic approach may be to follow a cohort of children being treated with the standard regimen, perform pharmacokinetic studies at multiple time points, ensure adherence to treatment and assess cure and relapses over 18-24 months. Such a study would provide valuable information on the effectiveness of drug dosages being used in the national program as well as provide an opportunity to study the role of other factors like age, HIV infection, nutritional status and acetylator status on patient outcomes.

Funding: None

Competing interests: None stated.

\section{REFERENCES}

1. Nelson LJ, Wells CD. Global epidemiology of childhood tuberculosis. Int $\mathrm{J}$ Tuberc Lung Dis 2004; 8: 636-647.
2. Fox W, Ellard GA, Mitchison DA. Studies on the treatment of tuberculosis undertaken by the British Medical Research Council Tuberculosis Units 1946-1986, with relevant subsequent publications. Int J Tuberc Lung Dis 1999; 3: S231-S279.

3. Jawahar MS. Current trends in chemotherapy of tuberculosis. Indian J Medical Res 2004; 120: 398417

4. Mwandumba HC, Squire SB. Fully intermittent dosing with drugs for treating tuberculosis in adults. Cochrane Database Syst Rev 2001; 4: CD000970.

5. Menon P, Lodha R, Sivanandan S, Kabra SK. Intermittent or daily short course chemotherapy for tuberculosis in children: meta-analysis of randomized clinical trials. Indian Pediatr 2010; 47: 67-73.

6. Gurumurthy P, Ramachandran G, Hemanth Kumar AK, Rajasekaran S, Padmapriyadarsini C, et al. Malabsorption of rifampicin and isoniazid in HIVinfected patients with and without tuberculosis. Clin Infect Dis 2004; 38: 230-233.

7. Schaaf HS, Parkin DP, Seifart HI, Werely CJ, Hesseling PB, van Helden PD, et al. Isoniazid pharmacokinetics in children treated for respiratory tuberculosis. Arch Dis Child 2005; 90:614-618.

8. Schaaf HS, Willemse M, Cilliers K, Labadarios D, Maritz JS, Hussey GD, et al. Rifampin pharmacokinetics in children, with and without human immunodeficiency virus infection, hospitalized for the management of severe forms of tuberculosis. BMC Med 2009; 7:19-29. 